\title{
Acid activation of bentonite clay for recycled automotive oil purification
}

\author{
Johanna Aguilar ${ }^{1}$, Cristina Almeida-Naranjo ${ }^{2}$, María B. Aldás ${ }^{1}$, Víctor H. Guerrero ${ }^{3, *}$ \\ ${ }^{1}$ Departament of Civil and Environmental Engineering, Escuela Politécnica Nacional, Quito, Ecuador \\ ${ }^{2}$ Departament of Mechanical Engineering, Escuela Politécnica Nacional, Quito, Ecuador \\ ${ }^{3}$ Departament of Materials, Escuela Politécnica Nacional, Quito, Ecuador
}

\begin{abstract}
The search for inexpensive and environmentally friendly alternatives for used motor oil (UMO) purification has become a topic of research. In this study, the use of bentonite clay modified by acid activation is proposed. Sulfuric acid, acetic acid ( $\mathrm{v}$-acid/w-clay ratio $=20,40$ and $60 \%$ ) and sulfuric/acetic mixtures (1:1 ratio) were used in the bentonite clay activation. The activated clays were used in the UMO treatment in a ratio of 1:4 w/v, using batch adsorption processes (contact time $=12 \mathrm{~min}$ ). To determine the structural and morphological modifications produced by the acid activation process, the clays were characterized by Fourier transform infrared spectroscopy, X-ray diffraction and scanning electron microscopy. The oil clarification efficiency was quantified by UV-Vis spectroscopy, acidity, alkalinity and viscosity index. It was determined that sulfuric acid and the sulfuric/acetic activations presented a similar bentonite structure transformation, which appears in the cations leaching of intermediate layer. The treated oil with the highest clarifications (with respect to UMO) were the ones treated using bentonite activated with sulfuric acid $40 \mathrm{v} / \mathrm{w} \%$ and sulfuric/acetic acid (1:1 ratio) with clarifications of 70 and $68 \%$, respectively. The oil treated with clay activated with sulfuric acid (40\%) reduced its viscosity, acidity and alkalinity by $23 \%, 80 \%$ and $29 \%$, respectively.
\end{abstract}

\section{Introduction}

Motor oils play an important role in the operation and performance of a vehicle, being one of the products in greatest demand. From 1991 to recent years, the annual global demand for lubricants has remained around 35 million tons [1]. Until 2015, the growing demand from emerging markets such as Brazil, Russia, India and China have led to a $2.6 \%$ increasing in demand for lubricating oils [2]. Because of the development of new technologies and the eminent industrial and automotive market growth, it is projected that the motor oil demand increases in time. The increasing motor oil demand combined with the decreasing petroleum availability $(67$ $\mathrm{L}$ of petroleum are required to produce $1 \mathrm{~L}$ of motor oil) require that $\mathrm{UMO}$ be reused (1.6 L of UMO is necessary to obtain $1 \mathrm{~L}$ of motor oil). In addition, UMO needs to be purified because is considered a dangerous waste (1 gal of UMO could contaminate 1 million gallons of drinking water) due to the presence of dust, heavy metals, polycyclic aromatic compounds (PAHs), polychlorinated biphenyls (PCBs), among others [1, 3-5].

Considering this, scientific community and governments have focused on developing efficient recovery UMO processes that could be applied at industrial scale [6]. Nowadays, the UMO purification technologies consist of four stages: (i) dewater and light defuel, (ii) de-asphalt, (iii) fractionation and (iv) finishing. Basically, the difference between these processes is de-asphalt and finishing. The finishing is the stage in which some substances (chlorine, nitrogen, sulfur, oxygen, peroxides, among others) are removed from UMO. These substances give color to the oil and increase its acidity degree (TAN). According to Jafari \& Hassanpour (2015), at the end of this stage UMO becomes clearer and its properties could return to those of a fresh motor oil. The finishing can be performed by adsorption process [7]. The most common adsorbent materials used are natural clay, activated clay, silica, activated carbon, etc. The evaluation of some individual techniques for the UMO regeneration, indicated that clay is more economical compared to other materials [8].

Bentonite clay is one of the most widely used clays, due to its physical-chemical properties and its ability to increase the space between its layers after being subjected to an activation process (acidic, alkaline, thermal or mixed) [9]. Acid activation is a chemical treatment that is generally carried out with hydrochloric or sulfuric acid. The increase in the adsorption capacity of bentonite depends on the activation conditions (acid concentration and type, temperature, contact time, acid/clay ratio, mixing speed, $\mathrm{pH}$ and particle size) and its composition. Therefore, it is important to find optimal operating conditions for each type of bentonite deposit available in a region [10]. Activated clay has improved surface properties (greater adsorption capacity), suitable

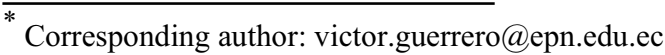


for a wide range of industrial applications such as the clarification of oils, wines, ciders, beers, wastewater treatments, etc. [6]. In wastewater treatments, activated clay has shown to be efficient in the removal of heavy metals, pesticides, and other hazardous contaminants [11-13]. In the oil recycling process, the use of activated bentonite has additional advantages such as reducing the residual sludge volume and the oil loss in the sludge [9]. Therefore, researches are carried out to optimize this type of processes. For instance, Oduola and Kwonna used sulfuric acid activated Ukpor clay to remove heavy metals and trace elements from UMO [14]. The highest removal of $\mathrm{Ca}, \mathrm{Pb}, \mathrm{Zn}$ and $\mathrm{Ba}$ were presented by clay activated with $2 \mathrm{~mol} / \mathrm{L}$ sulfuric acid, reaching removal efficiencies of $99.6,98.6,100$ and $90 \%$ respectively. Afolabi et. al (2016) reported that clays activated with sulfuric acid increase their specific surface area 22 times and their adsorption capacity 6 times. The purified oils improved their yield around $66 \%$ and their properties (flash point of $105.10{ }^{\circ} \mathrm{C}$, cloud point of $14.86{ }^{\circ} \mathrm{C}$, specific gravity of 0.881 , viscosity of $18.0 \mathrm{cSt}$ and iron content of $0.30 \mathrm{ppm}$ ) [15].

Considering the importance of UMO treatment, the aim of this work was to modify Ecuadorian bentonite clay by means of acid activation for be used in the oil purification.

\section{Materials and methods}

\subsection{Clay and used motor oil}

Bentonite clay was obtained in the city of Santa Elena (west coast of Ecuador) and used motor oil was obtained from an oil recycling company located in the city of Quito (northern Ecuador). The UMO used in this research previously went through the stages of dewater and light defuel, de-asphalt and fractionation.

\subsection{Clay acid activation}

The clay was washed for 30 minutes with distilled water to remove impurities such as sand, branches or roots. It was dried at $105{ }^{\circ} \mathrm{C}$ for $16 \mathrm{~h}$, crushed in a knife mill and sieved on a \# 200 mesh screen $(\leq 75 \mu \mathrm{m})$ [16].

The activation process was carried out according to the methods proposed by Aziz et al., (2011). $30 \mathrm{~g}$ of clay (previously washed and sieved) was weighed, distilled water was placed in a 10:1 ratio [17]. Then, in each wet clay sample, volumes of sulfuric acid ( $97 \mathrm{w} / \mathrm{w} \%)$, acetic acid $(99 \mathrm{w} / \mathrm{w} \%)$ and the mixture of both were added to have concentrations of $20 \%, 40 \%$ and $60 \%$ $\mathrm{v}($ acid $) / \mathrm{w}$ (clay) $\%$. The mixture (clay + water + acid) was stirred at $400 \mathrm{rpm}$ for $5 \mathrm{~h}$ at a $90{ }^{\circ} \mathrm{C}$, on a Thermo Scientific stirring and heating plate [18]. Finally, the mixtures were centrifuged at $3500 \mathrm{rpm}$ for 30 minutes. The supernatant was removed, and clay was dried at 105 ${ }^{\circ} \mathrm{C}$ for $16 \mathrm{~h}$. Dry clay was ground and sieved again (particle size $\leq 75 \mu \mathrm{m}$ ) [16].

\subsection{Used motor oil purification}

$20 \mathrm{~mL}$ of UMO was placed in beakers, the oil was heated to $90{ }^{\circ} \mathrm{C}$ with constant stirring at $200 \mathrm{rpm}$. Upon reaching temperature, activated clays and natural clay (washed and sieved clay) were placed at a ratio of 25 w/v\% with respect to the oil volume. The temperature was increased to $160{ }^{\circ} \mathrm{C}$. The procedure took place in approximately 12 minutes. Samples were cooled to 70 ${ }^{\circ} \mathrm{C}$ and filtered on medium porosity cellulose paper [8]. The oil clarification tests (finishing) were performed in duplicate.

\subsection{Analytical methods}

\subsubsection{Clay characterization}

Natural clay and activated clays were analyzed by Fourier Transform Infrared Spectrophotometry (FTIR), to determine the structural changes that occurred due to acid activation. The analyses were performed on a Perkin Elmer, Spectrum 100/Spotligth 200 in a wavelength range of 4000 to $500 \mathrm{~cm}^{-1}$.

The possible morphological and structural changes that natural clay could present after acid activation were determined by means of scanning electron microscopy (SEM) and Fourier transform infrared spectrophotometry (FTIR), respectively. SEM analyses were carried out in an ASPEX scanning electron microscope, PSEM eXpress model with a detection range of $500 \mathrm{~nm}$ to 5 $\mathrm{mm}$. FTIR analyses were performed on a Perkin Elmer, model Spectrum 100/Spotligth 200 in a wavelength range of 4000 to $500 \mathrm{~cm}^{-1}$.

The activated clays that presented greater efficiency in the clarification process of the UMO and a sample of natural clay, were analyzed by X-ray Diffractometry (XRD). The analysis was performed to determine the composition changes of each clay after acid activation. The analyses were performed in a PANalytical diffractometer, model EMPYREAN, using a copper Xray tube $(\mathrm{K} \alpha-\lambda=1.54056 \AA)$ at $45 \mathrm{kV}$ and $40 \mathrm{~mA}$. The diffractogram analysis was performed on the average of four measurements between the angles $5^{\circ}$ to $90^{\circ}(\Theta-2 \Theta$, Bragg-Brentano geometry) using the High Score Plus software.

\subsubsection{Oil characterization}

The purified UMO samples were analyzed by FTIR, UV-Vis spectrophotometry. In UV-VIS analysis, the purified UMO samples were previously diluted in hexane in a ratio of $1: 10$. Absorption analysis was carried out on a SPECORD 210 PLUS - 223F2101C spectrophotometer. To determine the wavelength with the highest absorbance, an UMO scan was performed. The peak with the highest absorbance occurred at 406 $\mathrm{nm}$, according to Aziz et al. (2011) this value is in the yellow region. Equation (1) was used to calculate the clay efficiency in UMO clarification [17].

$$
\mathrm{R}=\frac{\mathrm{AB}_{0}-\mathrm{AB}_{\mathrm{F}}}{\mathrm{AB}_{0}} \times 100
$$


where $\mathrm{R}$ is the efficiency calculated percentage, $\mathrm{ABO}$ is the amount of light absorbed by the UMO, and ABF is the amount of light absorbed by the treated UMO, using activated clay.

The color change due to the adsorption process was evaluated using ASTM D1500 color scale [19]. Viscosity, TAN and alkalinity index (TBN) analyses were performed on the treated UMO samples that showed greater clarification. The analyses were carried out on an ERALYTICS portable FTIR spectrophotometer, model ERASPEC OIL.

\section{Results and discussion}

\subsection{Clays characterization}

\subsubsection{FTIR analysis}

Blue lines (Figs. 1, 2 and 3) represent the natural clay FTIR spectrum. The first zone $\left(3750 \mathrm{~cm}^{-1}\right.$ to $\left.3100 \mathrm{~cm}^{-1}\right)$ is the characteristic region of the $\mathrm{O}-\mathrm{H}$ bonding stretch that lies between the tetrahedral and octahedral bentonite sheets $[10,18]$. The peak in the $3620 \mathrm{~cm}^{-1}$ band can be attributed to the stretching of $\mathrm{O}-\mathrm{H}$ bonds at structural $\mathrm{Al}_{2} \mathrm{OH}$ sites of dioctahedral smectites, i.e., aluminumrich bentonite. The $3650 \mathrm{~cm}^{-1}$ signal belongs to the stretching of the structural $\mathrm{O}-\mathrm{H}$ bond in the kaolinite network, confirming the presence of this mineral as an impurity [20]. Stretching in the $1050 \mathrm{~cm}^{-1}$ band is associated with $\mathrm{Si}-\mathrm{O}-\mathrm{Si}$ vibrations, a characteristic of bentonite clay group [21]. The band at $1438 \mathrm{~cm}^{-1}$ is due to the carbonate's presence [22], while the band at 790 $\mathrm{cm}^{-1}$ is associated with the presence of cristobalite [10]. The peak of the band at $865 \mathrm{~cm}^{-1}$ is assigned to the presence of the $\mathrm{AlFeOH}$ group that appears due to the iron and aluminum cations immersed in the molecular structure, and finally a peak in the $520 \mathrm{~cm}^{-1}$ band indicates the presence groups $\mathrm{Al}-\mathrm{O}-\mathrm{Si}[10,20]$.

Figs. 1, 2 and 3. show the FTIR spectrum of activated clays using sulfuric, acetic and sulfuric/acetic acid mixtures, respectively. Fig. 1. shows the FTIR spectra of clays that were activated with different concentration of the sulfuric acid $(20 \%=\mathrm{S} 20 \%, \quad 40 \%=\mathrm{S} 40 \%$ and $60 \%=\mathrm{S} 60 \%$ ). The clays activated with sulfuric acid $40 \%$ and $60 \%$ present an intensity decrease in the natural clay characteristic bands, reflecting a structural change because of the acid attack. These results suggest a significant decrease of cations that are part of the clay octahedral layer, which causes the loss of water and hydroxyl groups $\left(3750 \mathrm{~cm}^{-1}\right.$ to $\left.3100 \mathrm{~cm}^{-1}\right)$ [10]. The intensity decrease in $1438 \mathrm{~cm}^{-1}$ band shows the carbonates loss [22]. The persistence of the $1050 \mathrm{~cm}^{-1}$ band for the $\mathrm{S} 20 \%$ and $\mathrm{S} 40 \%$ clays indicates that the structural layer of the natural clay has not been destroyed. However, for the S60\% clay present a low intensity peak in this band [10]. Furthermore, in the $\mathrm{S} 40 \%$ and $\mathrm{S} 60 \%$ spectra, the decrease in the band intensity between $865 \mathrm{~cm}^{-1}$ to $520 \mathrm{~cm}^{-1}$ is noted, which suggests that the $\mathrm{Fe}$ and $\mathrm{Al}$ ions have been displaced from the natural clay structure $[10,20]$.

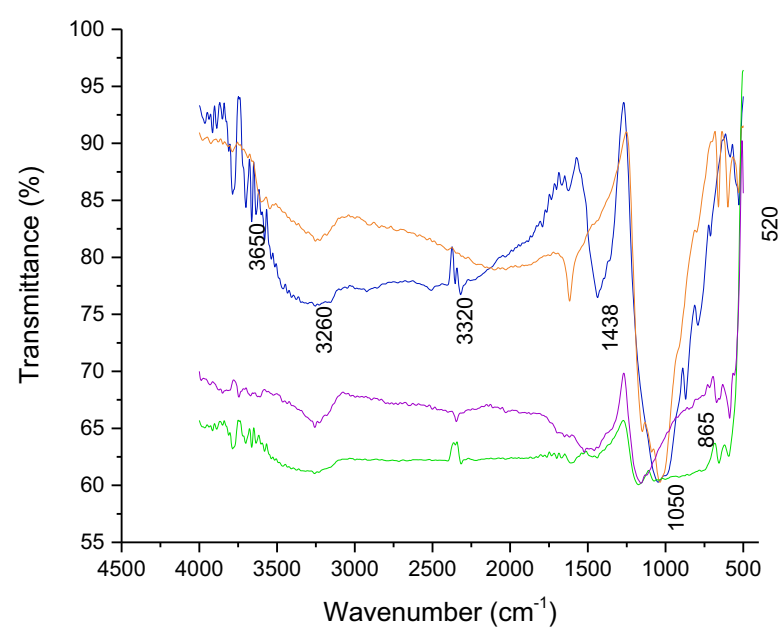

Fig. 1. FTIR spectra of activated clays with sulfuric acid. Blue line $=$ natural clay, orange line $=\mathrm{S} 20 \%$, green line $=\mathrm{S} 40 \%$ and purple line $=\mathrm{S} 60 \%$.

The FTIR spectra of the activated clays using acetic acid in different concentration $(20 \%=\mathrm{C} 20 \%$, $40 \%=\mathrm{C} 40 \%$ and $60 \%=\mathrm{C} 60 \%$ ) are shown in Fig. 2 . It is evident that the acid attack has not produced significant changes in the morphological structure of the natural clay. There is only a significant decrease in the intensity of the $1438 \mathrm{~cm}^{-1}$ band for samples $\mathrm{C} 40 \%$ and $\mathrm{C} 60 \%$, which indicates the carbonates depletion. While, in the $\mathrm{C} 20 \%$ clay spectrum, a lower decrease is observed in this peak [22].

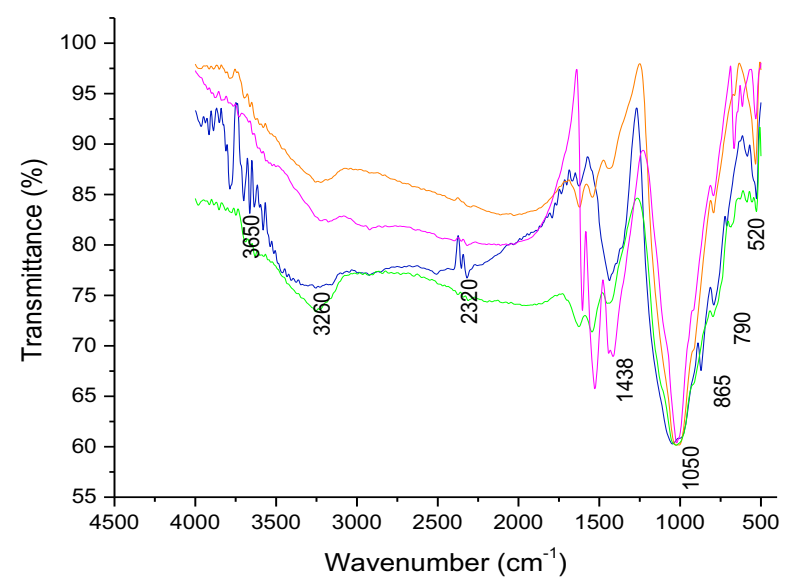

Fig. 2. FTIR spectra of activated clays with acetic acid. Blue line $=$ natural clay, orange line $=\mathrm{C} 20 \%$, green line $=\mathrm{C} 40 \%$ and purple line $=\mathrm{C} 60 \%$.

Fig. 3. shows the FTIR spectra of clays that were activated with different concentration of the sulfuric/acetic mixture $(20 \%=$ MIX $20 \%, 40 \%=$ MIX $40 \%$ and $60 \%=\mathrm{MIX} 60 \%$ ). It is observed that the intensity of the characteristic bands of the structure of the bentonite clay decreases for every sample, which reflects a structural change because of the acid attack. This behavior is like that of sulfuric acid activated clays. The difference is that with the mixture of acids the carbonate band disappears. The FTIR spectra of the different activations indicate the influence of the type and concentration of the acid on the clay activation. 


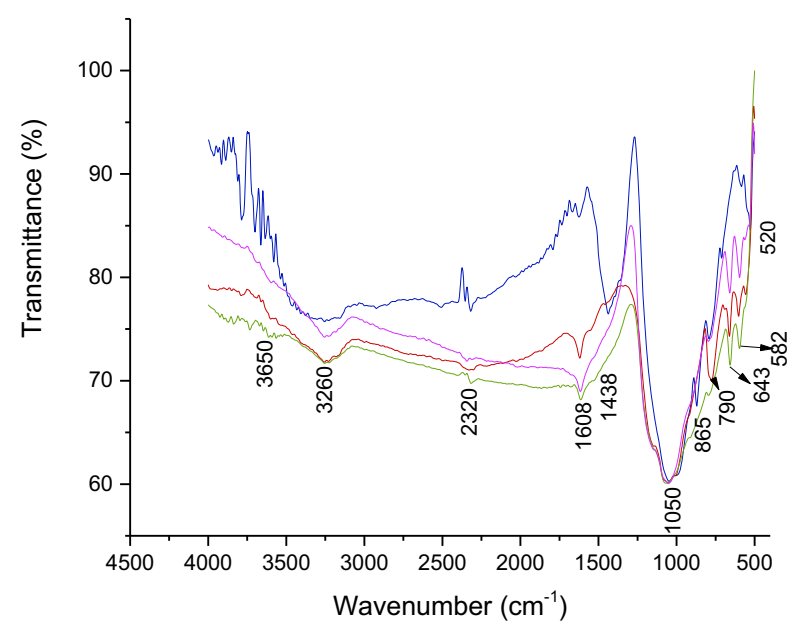

Fig. 3. FTIR spectra of activated clays with sulfuric/acetic acids. Blue line $=$ natural clay, red line $=\mathrm{MIX} 20 \%$, green line $=$ MIX $40 \%$ and purple line $=$ MIX $60 \%$.

\subsubsection{DRX analysis}

Fig. 4. shows the diffractogram of natural clay and clays activated with sulfuric acid (S40\%), acetic acid (C40\%), the mixture of both (MIX40\%). In the clay composition, the characteristic peaks of montmorillonite (M), gypsum $(\mathrm{G})$, cristobalite (Crs), calcite $(\mathrm{C})$, quartz (Q) and feldspars (F) are presented. A decrease in peak intensity in all activated clays demonstrates that changes have occurred in their mineral composition. The change is more visible to calcite, the $\mathrm{S} 40 \%$ activation process has produced the total degradation of this substance [16].

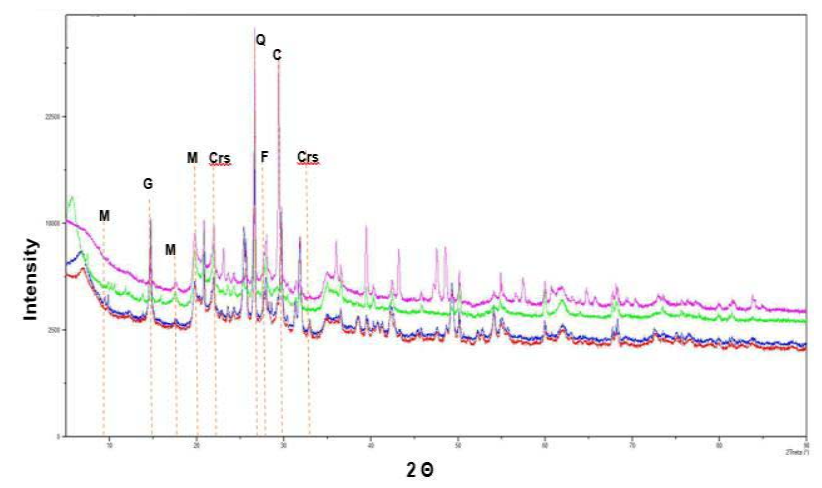

Fig. 4. DRX analysis. fuchsia line $=$ natural clay, blue line $=$ $\mathrm{S} 40 \%$, green line $=\mathrm{C} 40 \%$, red line $=\mathrm{MIX} 40 \%$.

\subsubsection{SEM analysis}

Comparing the SEM micrographs of the natural bentonite (Figure 5A) with the acid activated clays (Figures 5B, 5C and 5D), changes in the clay morphology are showed after their activation. The modified solids morphology is related to the exfoliation or delamination of the mineral [20]. Delamination could be related to the results of FTIR analyses that show structural changes. Macroscopically a change in activated clays coloration can be observed (Fig. 5e.), that is produced by the increase in the interlaminar space of bentonite layers due to the organic matter and carbonates decomposition [23].

a)

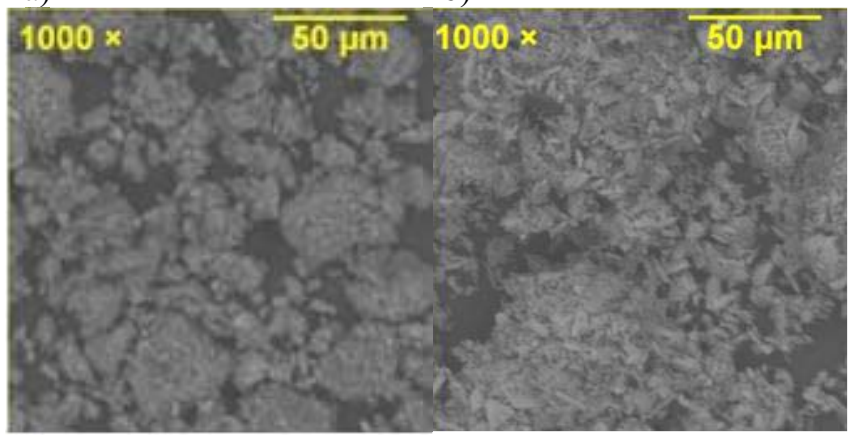

c)

d)

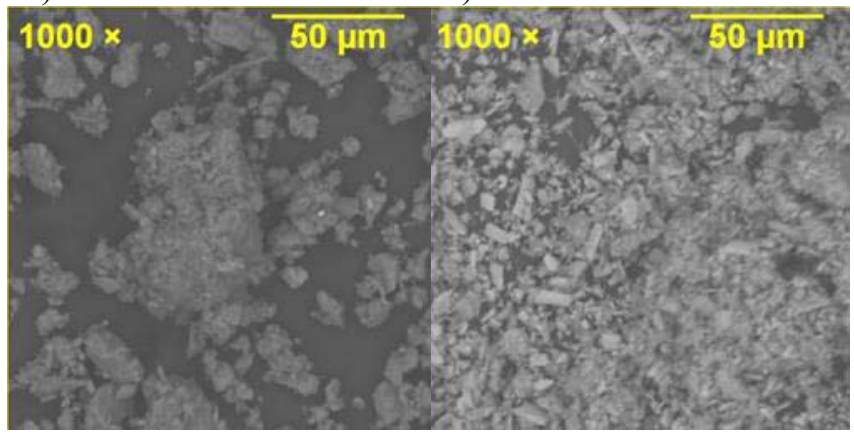

e)

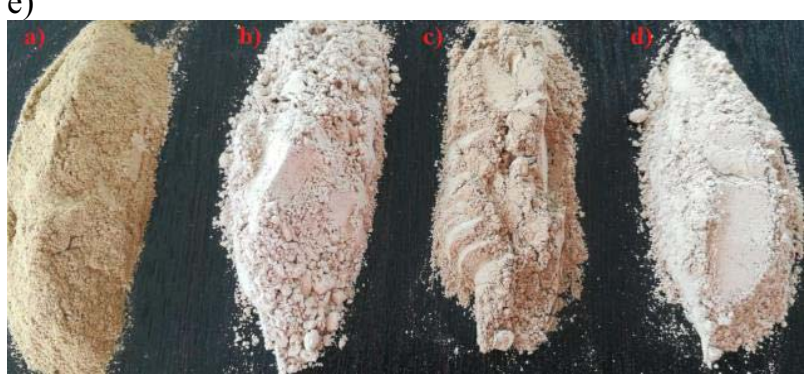

Fig. 5. SEM analysis. a) Natural clay, b) activated clay with $\mathrm{S} 40 \%$, c) activated clay with $\mathrm{C} 40 \%$, d) activated clay with MIX $40 \%$, e) Color differences between clays.

\subsection{Oil characterization}

\subsubsection{FTIR analysis}

Fig. 6. shows the FTIR spectrum of UMO and UMO treated with the activated clays $\mathrm{S} 40 \%$ and MIX $40 \%$. The peaks that represent typical components of UMO are presented, the bands between $3750 \mathrm{~cm}^{-1}$ to $3100 \mathrm{~cm}^{-1}$ are attributed to $\mathrm{OH}$ groups, which reflects the water content in UMO that is usually incorporated in it during its use in the automotive. The amount of water contained in the oil decreases markedly after its treatment $(\mathrm{OH}$ bands decrease) [24]. The bands (2922 $\mathrm{cm}^{-1}$ and $\left.1458 \mathrm{~cm}^{-1}\right)$ corresponding to the alkanes functional group $(\mathrm{C}-\mathrm{H})$ show a slight decrease in intensity. The carboxylic acids functional group $\left(2322 \mathrm{~cm}^{-1}\right)$ band indicates the presence of oxidized primary products at high temperatures. While the one located in the $1375 \mathrm{~cm}^{-1}$ band represents the $\mathrm{C}-\mathrm{H}$ bond of the $\mathrm{CH}_{3}$ group, this band also shows a decrease in intensity after treatment $[15,16]$. The spectral characteristics around $800 \mathrm{~cm}^{-1}\left(772 \mathrm{~cm}^{-1}\right)$ confirm the 
aromatic content that indicates if there is fuel present in the UMO. Thus, after the adsorption using the activated clays $\mathrm{S} 40 \%$ and $\mathrm{MIX} 40 \%$, the intensity of the UMO bands decrease, this confirm that clays are efficient [13, 21].

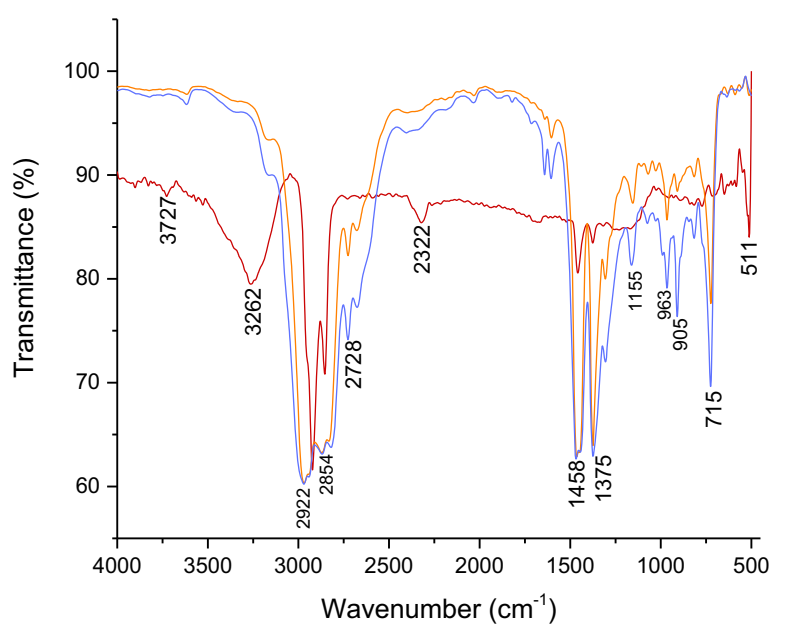

Fig. 6. FTIR spectra of UMO. Red line=non treatment UMO, orange line $=$ treated with activated clay $\mathrm{S} 40 \%$, blue line $=$ treated with activated clay mix $40 \%$ (T MIX40).

\subsubsection{UV-Vis analysis}

Table 1 details the results obtained in the UV-Vis analysis and the efficiency in batch adsorption process. The UMO sample had $65.6 \%$ absorbance, a value that indicates that the UMO contains high concentrations of chlorine, nitrogen, sulphur, oxygen and peroxides that give colour to the lubricating oil [7]. The UMO treated with natural clay presents an adsorption efficiency of $21.2 \%$. On the other hand, the UMO treated with clays activated with S40\% and with MIX40\% show efficiencies around $69.5 \%$ and $68.1 \%$, respectively. The absorbance reduction indicates that some quantity of the contaminants has been removed.

Table 1. Oil absorbance and clay adsorption efficiency.

\begin{tabular}{|c|c|c|}
\hline Clay used & $\begin{array}{c}\text { Oil sample } \\
\text { absorbance } \\
(\%)\end{array}$ & $\begin{array}{c}\text { Average } \\
\text { adsorption } \\
\text { efficiency } \\
\text { (\%) }\end{array}$ \\
\hline None & 65.6 & - \\
\hline Natural clay & 51.7 & 21.2 \\
\hline S20\% & 34.4 & 47.5 \\
\hline S40\% & 20.0 & 69.5 \\
\hline S60\% & 38.4 & 41.5 \\
\hline C20\% & 35.2 & 46.3 \\
\hline C40\% & 30.0 & 54.3 \\
\hline C60\% & 36.2 & 44.8 \\
\hline MIX20\% & 27.9 & 57.5 \\
\hline MIX40\% & 20.9 & 68.1 \\
\hline MIX60\% & 31.4 & 52.1 \\
\hline
\end{tabular}

The increase in the activated clay adsorption efficiency respect to that of natural clay obtained in this study is almost twice (48.3\%) that achieved by Afolabi et. al (2016). The authors reported a $26.3 \%$ increase in the UMO purification efficiency, using clay activated with sulfuric acid compared to natural clay [15].

In Fig. 7. some UMO samples with different treatments are presented. The untreated UMO sample was color 8 on the ASTM D1500 color scale. The UMO treated with S40\% activated clay and MIX $40 \%$ activated clay are similar and correspond to color 2 . While the color obtained with treatments using $\mathrm{C} 40 \%$ and MIX20\% activated clays was similar in both samples (color 3.5). This color was lighter than that obtained in UMO treated with natural clay (color 5) [19].

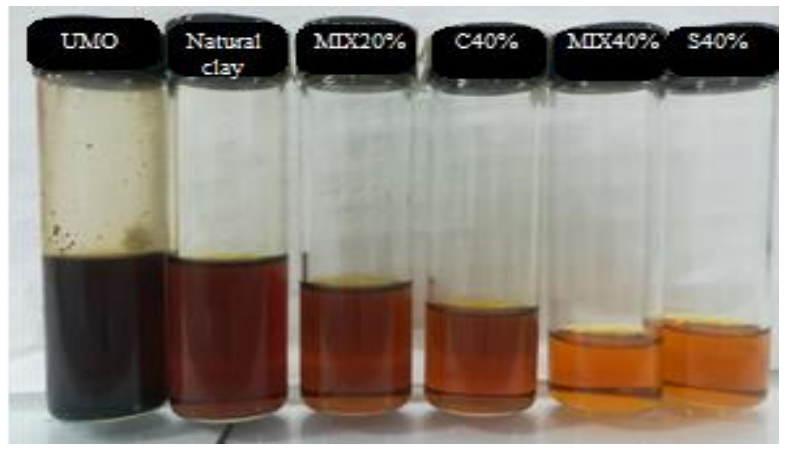

Fig. 7. Comparison of UMO treated with different clays using ASTM D1500 color scale.

\subsubsection{UV-Vis analysis}

Table 2 details the parameters evaluated to determine the treated oil quality. The higher viscosity of the UMO compared to the treated UMO indicates the contamination presence in the oil. Polymerized products dissolved or suspended and oxidized in the oil could cause an increase in its viscosity. The UMO viscosity levels measured at $40{ }^{\circ} \mathrm{C}$ and $100{ }^{\circ} \mathrm{C}$ decreased after being treated with natural and activated clay. The same behavior was presented for the TAN and the TBN, reaching reductions of 80 and $29 \%$, respectively. The decrease indicates that the clays used in the treatment were able to remove part of the UMO contaminants, improving its viscosity, TAN and TBN [16]. These results are similar to those obtained by Andargachew (2016), who achieved a decrease in the TAN value $(82 \%$ approximately) in the UMO treated using activated clays [8].

Table 2. Parameters evaluated to determine the treated oil quality.

\begin{tabular}{|c|c|c|c|c|}
\hline \multirow{2}{*}{ Treatment } & \multicolumn{2}{|c|}{$\begin{array}{c}\text { Viscosity } \\
\text { (cSt) }\end{array}$} & \multirow{2}{*}{$\begin{array}{c}\text { TAN } \\
(\mathbf{m g ~ K O H} \\
\left.\mathbf{g}^{-1}\right)\end{array}$} & $\begin{array}{c}\text { TBN } \\
\left(\mathbf{m g ~ K O H ~ g}^{-1}\right)\end{array}$ \\
\cline { 2 - 3 } & $\mathbf{4 0}^{\circ} \mathbf{C}$ & $\mathbf{1 0 0}^{\circ} \mathbf{C}$ & 0.4 & 3.8 \\
\hline None & 39.6 & 7.6 & 0.2 & 2.7 \\
\hline $\begin{array}{c}\text { Natural } \\
\text { Bentonite }\end{array}$ & 34.1 & 6.6 & 0.2 & 2.7 \\
\hline S40\% clay & 31.1 & 7.0 & 0.1 & \\
\hline
\end{tabular}

\section{Conclusion}

Bentonite is a low cost and widely available material, that increases its adsorption capacity by modifications with sulfuric acid, acetic acid and their mixtures. The 
modified bentonite presents adequate characteristics to remove contaminants from UMO. The oil treated with clay activated with sulfuric acid $(40 \mathrm{w} / \mathrm{v} \%)$ reduces its viscosity, acidity and alkalinity $23 \%, 80 \%$ and $29 \%$, respectively. The clays activated with $\mathrm{S} 40 \%$ sulfuric acid and MIX40\% sulfuric/acetic acid presented similar efficiencies in the removal of contaminants, 70 and $68 \%$, respectively. This indicates that half of sulfuric acid could be replaced by acetic acid, which is less expensive and less aggressive due to its organic nature. The acid modification using a MIX $40 \%$ is a relatively simple process that could be scaled to an industrial level.

\section{References}

1. L. Wei, H. Duan, S. Chen, D. Jia, Y. Jin, X. Qian, J. Liu, J. Li. P. I. Mech. Eng. J-J Eng., 233, 281(2018)

2. Q. Jiang, Y. Xu, W. Xin, Z. Song, Q. Song, M. Ke. Pet. Sci 9, 558 (2012)

3. K. Pramanik. Renew. Energy, 28, 239 (2003).

4. J. D. Udonne. J. Petrol. Sci. Eng. 2, 12 (2011).

5. H. Shabanzade, A. Salem, S. Salem. Spectrochim Acta A. 202, 214 (2018).

6. P. Komadel. Appl. 131, 84 (2016).

7. A. J. Jafari, M. Hassanpour. Resour. Conserv. Recycl, 103, 179 (2015)

8. H. Andargachew. Diss. Addis Ababa University, (2014)

9. E. A. Emam, IE, 2, 19, (2018)

10. M. K. Motlagh, A. A. Youzbashi, Z. A. Rigi. Iranian Mater. Sci. 8, 50 (2011)
11. B. Te, B. Wichitsathian, \& C. Yossapol, IJESD, 6(11), 799-804 (2015).

12. N. Boroomand and Z. Shokria, IJESD, 8(2), 88-92, (2017).

13. S. Tha-in, H. A. Dau, \& K. Dumri, IJESD, 4(4), 415-418 (2013).

14. M. K Oduola., O. O. Okwonna. Int. J. of Eng. Res. Sci., 2, 113 (2016)

15. E. A. Afolabi, A. S. Kovo, D. A. Olalekan, A. Jibrin, A. S. Abdulkarrem, B. Suleimam. Leonardo J. Sci., 28, 1 (2016)

16. R. Abu-Elella, M. Ossman, R. Farouq, M. AbdElfatah. Int. J. Chem. Biochem. Sci., 7, 57(2015).

17. B. K. Aziz, M. A. Abdullah, K. J. Jubrael. Asian J. Chem., 23, 2449 (2011)

18. K. G. Bhattacharyya, S. SenGupta, S., G. K. Sarma, Appl. Clay. Sci., 99 (2014)

19. ASTM D1500. Standard Test Method for ASTM Color of Petroleum Products (ASTM Color Scale, 2012). Annual Book of Standards.

20. J. Torres, N. Sanabria, J. Carriazo. Rev. Colombiana de Química, 42, 44(2013).

21. P. Belousov, V. Krupskaya, O. Dorzhieva, M. Timofeeva, S. Zakusin, A. Zhukhlistov, E. Tyupina. Minerals, 7, 49(2017).

22. A. M. Motawie, M. M. Madany, A. Z. El-Dakrory, H. M. Osman, E. A. Ismail, M. M. Badr, D.E. Abulyazied. Egypt. J. Pet., 23, 331(2014)

23. S. Chakroun, M. Herchi, W. Mechti, M. E. Gaied, Environ. Sci. Pollut. R., 24, 22557 (2017).

24. M. C. Garry, J. Bowman. Thermo Fisher Scientific (2007). 